\title{
Análisis de Métodos de Medición de Complejidad de Imagen
}

\section{Image Complexity Measurement Methods: A Survey}

Luis Madrid-Herrera' ${ }^{1}$

Imadrid@itchihuahua.edu.mx

Mario Ignacio Chacón-Murguía ${ }^{1}$

mchacon@ieee.org

Juan Alberto Ramírez-Quintana

jaramirez@itchihuahua.edu.mx

'Laboratorio de Sistemas de Percepción Visual con Aplicaciones en Robótica, Tecnológico Nacional de México/ I.T. Chihuahua, México. 
Resumen. La complejidad de imágenes ha sido estudiada con la finalidad proponer algoritmos computacionales que puedan estimarla simulando el criterio humano, para su aplicación en diversas áreas de procesamiento de imágenes. En este artículo se presenta un estudio de los métodos para determinar la complejidad de imágenes publicados recientemente, se realiza una clasificación basada en las características utilizadas para determinar la complejidad de una imagen y se describen brevemente. En total se analizaron 28 artículos desde el año 2005 a la actualidad, donde se encontraron 34 métodos, los cuales están basados en enfoques computacionales y enfoques humanos. Las categorías en las que se clasifican son: información de bordes, información del color y/o intensidad, grado de compresión, combinado, criterio humano y reacción humana. También, se dan a conocer las bases de datos utilizadas para evaluar los métodos de medición. Por último, se realiza un análisis de la cantidad de métodos que se encuentran en cada categoría, características más utilizadas, cantidad de métodos que se publicaron por año y sus aplicaciones.

Palabras clave. Complejidad de imágenes, Complejidad visual, Aplicaciones de complejidad de imagen, Seguimiento de ojos, EEG, MEG.

Abstract. Image complexity has been studied with the purpose to propose computational algorithms that may simulate the human behavior for applications in diverse image processing areas. This paper presents a survey of recently published image complexity methods. The paper describes a classification based on the used characteristics to determine image complexity followed by a brief explanation. 28 papers from 2005 to 2018 were analyzed. From this analysis, 34 methods were determined. These methods are based on computational and human approaches. The classification categories are edge information, color and/or intensity information, level of compression, combined, human criterion, and human reaction. The paper also describes the datasets commonly used to evaluate the methods. Finally, it is performed an analysis of the methods in each category, main used characteristics, amount of methods published by year and their applications.

Keywords. Image Complexity, Visual Complexity, Image Complexity Applications, Eye Tracking, EEG, MEG. 


\section{Introducción}

La complejidad de imágenes es un término que en la actualidad no se encuentra formalmente definido, por lo que su definición varía con cada autor. Kolmogorov estudia la complejidad desde el punto de vista computacional y la define relativamente como la longitud del programa más corto que pueda generar un objeto solamente con elementos básicos (Kolmogorov, 1968). El término complejidad visual fue dado a conocer por Snodgrass y Vanderwart (Snodgrass \& Vanderwart, 1980) para referirse a la cantidad de detalles o que tan intricado es el entorno que percibimos mediante el sentido de la vista (Alexandra Forsythe, 2009), y a partir de esta definición se comenzó a utilizar el término complejidad de imágenes, refiriéndose a que tan compleja es una imagen en específico.

Sin embargo, el término complejidad de imágenes continúa siendo subjetivo, ya que no existe una manera concreta para medirla. Lo anterior, llevó a algunos investigadores a trabajar en el diseño de algoritmos para medir la complejidad de las imágenes y comúnmente es definida mediante el método que se utiliza para medirla. En (Chikhman, Bondarko, Danilova, Goluzina, \& Shelepin, 2012) mencionan diversas definiciones para la complejidad de imagen, una de ellas se refiere como una medida de aleatoriedad que tiene algo en común con la entropía de Shannon de la imagen, otra menciona que se puede definir cómo el número de frecuencias activas espaciales o número de Wavelets activas, y también que la complejidad se puede estimar como el producto de la media cuadrática de la distribución espacial de frecuencias y el área de la imagen. Para (Chacón, Corral S., \& Sandoval R., 2007) el término complejidad de imagen está relacionado a cuánta atención requiere una persona para reconocer y detectar objetos en una imagen. En (Huo, 2016a) se relaciona la complejidad de imagen con la atención visual y el trabajo de la memoria que requiere una persona para entender la imagen, por lo que consideran que está relacionada con la cantidad de objetos contenidos en la imagen. En (Snodgrass \& Vanderwart, 1980) definen complejidad de imagen como la cantidad de detalles y que tan confusa es una imagen y en (Heaps \& Handel, 1999) como el grado de dificultad de dar una descripción verbal de la imagen (Ciocca, Corchs, \& Gasparini, 2015).

Dentro de las aplicaciones de medir la complejidad de imágenes se encontró que: es utilizada para la definición de los bordes de interés en una imagen (Chacón, Aguilar D., \& Delgado S., 2002), para obtener el grado de compresión de las imágenes (Chikhman et al., 2012; A. Forsythe, Nadal, Sheehy, CelaConde, \& Sawey, 2011), un ajuste automático de la tasa de transferencia de bits en transmisiones de videos (Da Silva, Courboulay, \& Estraillier, 2011), para definir el grado de marca de agua sin distorsionar las imágenes (Yaghmaee \& Jamzad, 2010), evaluar cómo afecta la complejidad de los paisajes urbanos al manejar (Cavalcante et al., 2014), para medir el grado de dificultad al fijar la 
atención en los objetos de interés dependiendo el tipo de fondo utilizado en el diseño de páginas web (Huo, 2016b), entre otras.

La contribución de este artículo consiste en presentar los métodos para determinar la complejidad de imágenes existentes en la literatura y proponer una clasificación basada en la técnica que se utiliza para medirla ya sea por enfoques computacionales o enfoques humanos, agrupándolas por categorías con base en las características utilizadas. Además, se presentan las bases de datos reportadas en la literatura utilizadas para realizar estas mediciones.

Este artículo se organiza de la siguiente manera. En la Sección 2 se presentan los métodos para determinar la complejidad de imágenes y la clasificación por tipo de técnica y características. En la Sección 3 se da un pequeño resumen de los métodos basadas en enfoques computacionales y en la Sección 4 de los basados en enfoques humanos. Seguidamente en la Sección 5 se dan a conocer y se describen brevemente las bases de datos utilizadas para evaluar la complejidad de imágenes. Por último, en la Sección 6 se presenta el análisis y en la Sección 7 los resultados y conclusiones.

\section{Clasificación general}

En esta sección se presenta la clasificación general de los métodos para determinar la complejidad de imágenes estudiados. En total se analizaron 28 artículos del 2005 a la actualidad, de los cuales se obtuvieron 34 métodos de complejidad de imagen. En la Tabla 1 se muestra a que categoría y tipo de técnica pertenece cada uno de los 28 artículos revisados y en la columna características se muestra en que se basa su medición de complejidad.

Los métodos son agrupados en dos tipos de técnicas para determinar la complejidad de las imágenes: enfoques computacionales y enfoques humanos. Los enfoques computacionales son divididos en cuatro categorías, las cuales son: información de bordes, información del color y/o intensidad, grado de compresión, combinado. Por otro lado, los enfoques humanos se dividen en dos categorías: criterio humano y reacción humana. A continuación, se describen cada una de ellas. 


\begin{tabular}{|c|c|c|c|}
\hline & Categorias & Caracteristicas & Articulos \\
\hline \multirow{20}{*}{ 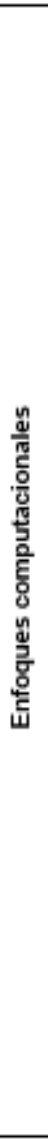 } & \multirow{2}{*}{$\begin{array}{l}\text { Información } \\
\text { de bordes }\end{array}$} & $\begin{array}{l}\text { Mediante un sistema difuso basado en el } \\
\text { porcentaje de niveles de bordes }\end{array}$ & (Chacón et al., 2007) \\
\hline & & Cantidad y distribución de bordes & (Machado et al., 2015) \\
\hline & \multirow{7}{*}{$\begin{array}{l}\text { Información } \\
\text { de color y/o } \\
\text { intensidad }\end{array}$} & Se basa en los colores y la resolución & (Ivanovici, 2017) \\
\hline & & Dispersión de color e intensidad de los piceles & (Perki \& Hyvarinen, 2009) \\
\hline & & $\begin{array}{l}\text { Complejidad de color, la saturación y la simetría } \\
\text { como características }\end{array}$ & $\begin{array}{l}\text { (Guo, Kurita, Muraki Asano, \& Asano, } \\
\text { 2013) }\end{array}$ \\
\hline & & $\begin{array}{c}\text { Información de las regiones obtenidas por medio } \\
\text { de segmentación e histograma }\end{array}$ & (Rigau, Feicas, \& Sbert, 2005) \\
\hline & & $\begin{array}{c}\text { Basado en características de contraste local y } \\
\text { frecuencia espacial }\end{array}$ & (Cavalcante et al., 2014) \\
\hline & & Basado en la medida difusa de la entropía & $\begin{array}{l}\text { (Cardaci, Di Gesú, Petrou, \& Tabacchi, } \\
\text { 2009) }\end{array}$ \\
\hline & & Aproximación de la entropía & (Pham \& Yan, 2018) \\
\hline & $\begin{array}{c}\text { Grado de } \\
\text { compresión }\end{array}$ & $\begin{array}{l}\text { Análisis del grado de compresión GIF y de la } \\
\text { dimensión fractal }\end{array}$ & (A. Forsythe et al., 2011) \\
\hline & \multirow{10}{*}{ Combinado } & Combinación líneal de características & $\begin{array}{l}\text { (S. E. Corchs, Ciocca, Bricolo, \& } \\
\text { Gasparini, 2016) }\end{array}$ \\
\hline & & Textura, bordes y región significativa & (Chen, Duan, Zhu, Qian, \& Xiso, 2015) \\
\hline & & $\begin{array}{c}\text { Utilizan características espaciales, espacio- } \\
\text { frecuenciales, una combinación de las } \\
\text { propiedades del espacio y la transformada de } \\
\text { Fourier, y el tamaño de la imagen codificada en } \\
\text { formato JPEG }\end{array}$ & (Chikhman et al., 2012) \\
\hline & & $\begin{array}{l}\text { Intensidad, el contraste, la localización, los bordes } \\
\text { y la textura }\end{array}$ & (Yaghmaee \& Jamzad, 2010) \\
\hline & & Mapas de atención, sobresalientes y de calor & (Da Silva et al., 2011) \\
\hline & & $\begin{array}{c}\text { Transformación de Características Invariables a la } \\
\text { Escala y } K \text {-means }\end{array}$ & (Huo, 2016b) \\
\hline & & $\begin{array}{l}\text { La regularidad, rugosidad, direccionalidad, } \\
\text { densidad y comprensibilidad }\end{array}$ & $\begin{array}{l}\text { (Guo, Assno, Asano, Kurita, \& Li, } \\
\text { 2012) }\end{array}$ \\
\hline & & $\begin{array}{l}\text { Información de color, bordes y grado de } \\
\text { compresión }\end{array}$ & (Purchase, Freeman, \& Hamer, 2012) \\
\hline & & $\begin{array}{c}\text { Coloración, saturación, área, grupos de texto, } \\
\text { simetría y equilibrio }\end{array}$ & (Reinecke et al., 2013) \\
\hline & & $\begin{array}{l}\text { Información de la composición, estadística y de la } \\
\text { distribución }\end{array}$ & (Sun, Yamasaki, \& Aizawa, 2015) \\
\hline \multirow{7}{*}{ 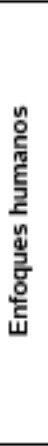 } & \multirow[b]{3}{*}{$\begin{array}{c}\text { Criterio } \\
\text { humano }\end{array}$} & Basado en el tiempo de observación & (Da Silva et al., 2011) \\
\hline & & Mediante un cuestionario & (Cardaci et al., 2009) \\
\hline & & Media del criterio humano & $\begin{array}{l}\text { (Cavalcante et al., 2014) (S. E. Corchs } \\
\text { et al., 2016) (Purchase et al., 2012) } \\
\text { (Sun et al., 2015) (Ramanarayanan, } \\
\text { Bala, Ferwerda, \& Walter, 2008) } \\
\text { (Palumbo, Makin, \& Bertamini, 2014) } \\
\end{array}$ \\
\hline & \multirow{4}{*}{$\begin{array}{l}\text { Reacción } \\
\text { humana }\end{array}$} & Análisis de movimiento ocular & $\begin{array}{c}\text { (Bonev, Chuang, \& Escolano, 2013) } \\
\text { (White, Hirotani, \& Liversedge, 2012) } \\
\text { (Roth, Tuch, Mekler, Bargas-Avila, \& } \\
\text { Opwis, 2013) }\end{array}$ \\
\hline & & Señales electroencefalográficas (EEG) & (Huo, 2016a) \\
\hline & & Señales magnetoencefalográficas (MEG) & (Cho et al., 2016) \\
\hline & & Señales EEG y MEG & (Hsu, Lee, \& Marantz, 2011) \\
\hline
\end{tabular}

Tabla 1. Clasificación de los métodos para determinar la complejidad de imágenes.

\section{Enfoques computacionales}

Los métodos para determinar la complejidad de imágenes por medio de técnicas computacionales son aquellos en los que el cálculo de la complejidad se realiza mediante algoritmos que utilizan recursos informáticos. A continuación, en esta sección se describen brevemente los métodos encontrados basados en este tipo de técnica. 


\subsection{Información de bordes}

Los bordes han sido utilizados para medir la complejidad de las imágenes debido a que se considera que estos están directamente relacionados, ya que una imagen difícil de describir normalmente cuenta con una gran cantidad de objetos y detalles, y estos están relacionados con la cantidad de bordes. Diversos trabajos utilizan los bordes como características, sin embargo, no es la única característica que utilizan, es por esto que no todos quedan dentro de esta categoría. En total, se encontraron dos métodos donde se utilizan los bordes como característica principal para determinar la complejidad, uno de ellos es propuesto en (Chacón et al., 2007), donde se basan en el análisis de los porcentajes de niveles de bordes contenidos en toda la imagen. La información que proveen los bordes es procesada por medio de lógica difusa y se calcula el grado de pertenencia de las imágenes a las clases: Poco Compleja, Más o Menos Compleja y Muy Compleja, las cuales son determinadas mediante el algoritmo de agrupamiento difuso (fuzzy C-means) descrito en (Corral S., 2003). Los resultados de la medición de complejidad son consistentes y se correlacionan con el criterio humano.

Este método para determinar la complejidad de imágenes fue probado en una base de datos con 150 imágenes. La ventaja principal es que no se involucra el criterio humano, lo que hace que sea muy consistente. Como aplicación del método, se encuentra un algoritmo detector de bordes, el cual utiliza la complejidad de la imagen para determinar cuáles niveles de bordes serán incluidos en la imagen de bordes. También, en (Machado et al., 2015) miden la complejidad de las imágenes mediante el uso de operaciones de detección de bordes, algunas métricas basadas en la compresión de imágenes y la ley Zipf. La información que proveen los bordes es extraída respecto a su cantidad y su distribución, ya que consideran que una imagen es más compleja si cuenta con una cantidad de bordes y su distribución es menos predecible. Para extraer los bordes se utilizan filtros de Canny y de Sobel. Las métricas basadas en compresión son utilizadas ya que existe una relación entre la complejidad y la compresión, debido a que una imagen poco compleja tiene información redundante y predecible, por lo tanto, esta información puede ser representada con menos datos, es decir que puede ser comprimida; y una imagen con complejidad alta, la información no puede ser predicha tan fácilmente, por lo tanto, se vuelve más difícil comprimirla ya que no se quiere perder información importante.

La ley de Zipf es utilizada para calcular el rango y tamaño de frecuencia. Para calcular el rango de frecuencia Zipf es necesario contar el número de veces que se presenta cierta intensidad en los pixeles y ordenarlos. El tamaño de frecuencia Zipf es la diferencia de intensidad que tiene cada pixel con sus vecinos. Los resultados demuestran que la medición por medio de la densidad 
de bordes y el grado de compresión fueron el mejor estimador de la complejidad de imágenes de acuerdo con el criterio humano.

\subsection{Información del color y/o intensidad}

Dentro de esta categoría se encuentran los métodos para determinar la complejidad de imágenes que utilizan características extraídas directamente de la información del color y/o intensidad de los pixeles, uno de ellos es el método propuesto en (Ivanovici, 2017), el cual se basa solamente en los colores y la resolución con la finalidad de mostrar que estas características tienen propiedades interesantes y al ser simples de procesar, el método se vuelve computacionalmente muy eficiente y puede ser utilizado en aplicaciones de tiempo real. Para proponer el método de complejidad estudian el comportamiento de la entropía de Shannon y de esta manera tratan de que tenga un comportamiento parcialmente similar.

Por lo que, el cálculo de complejidad de imagen es el número normalizado de colores distintivos en un soporte espacial definido. Además, se realizaron pruebas con algunas imágenes artificiales donde se varió el número de colores y la resolución, y se extendió su análisis a la base de datos VisTex (Technology, 2002). Los resultados muestran que este sencillo enfoque para la medición de la complejidad de imágenes se correlaciona con algunas otras características como la entropía. En (Perki \& Hyvarinen, 2009) presentan un método para evaluar la complejidad de imágenes basado en el Análisis de Componentes Independientes (ICA por sus siglas en inglés). La finalidad de utilizar ICA es tomarlo como una medida de dispersión del color y la intensidad de los pixeles, es decir, se mide el grado de no semejanza a la distribución Gaussiana y se aproxima a una medición de la entropía. Este método muestra que la complejidad es poca si los componentes son escasos, o si los datos están concentrados en subespacios pequeños. Por medio de una Máquina de Vectores de Soporte (SVM por sus siglas en inglés) en (Guo et al., 2013) clasifican a las imágenes como Poco Compleja, Medio Compleja y Muy compleja, un resultado similar al realizado en (Chacón et al., 2007), las características globales que se utilizan como entrada del clasificador son: la medida de complejidad de color (Yoon \& Kweon, 2001), la saturación y la simetría.

Para encontrar las características locales primero se segmenta la imagen y se juntan las regiones con color similar y adyacencia (Ning, Zhang, Zhang, \& Wu, 2010), posteriormente de cada región se extrae la saturación, el contraste y la intensidad del color, además, también se utiliza el número de segmentos creados, el área y la forma de los segmentos. Este método lo utilizan para evaluar la complejidad visual de las pinturas artísticas y obtienen correlación con el criterio humano, como trabajo futuro se aplicará en diferentes tipos de imágenes. Otro método que se basa en las regiones de la imagen pero con 
información del histograma, es el propuesto en (Rigau et al., 2005). En él, se relacionan tanto la complejidad de la imagen como la entropía de la intensidad de su histograma. El proceso para calcular la complejidad toma como entrada la imagen segmentada y el histograma dividido por regiones. De la imagen segmentada se obtiene el número de regiones que se formaron, tomando en cuenta que entre más regiones contenga la imagen más compleja será y el histograma provee información de intensidad de cada una de las regiones. Este método demuestra otra manera en la cual puede ser medida la complejidad de las imágenes, siendo afectada directamente por la resolución de las imágenes, el contraste y la cantidad de detalles contenidos. Por otro lado, en (Cavalcante et al., 2014) proponen un método para evaluar la complejidad percibida de los paisajes urbanos basándose en la estadística del contraste local y la frecuencia espacial. Las características que se extraen del contraste son la media y la desviación estándar. La frecuencia espacial es segmentada por medio de mapas de Kurtosis para obtener su valor y la oblicuidad. El objetivo de evaluar la complejidad de estos paisajes es observar cómo afectan a los conductores, con el fin de evitar incidentes como el no divisar a algún peatón. Los resultados demuestran que se tiene una alta correlación con la subjetividad del criterio humano y tiene buen desempeño también con paisajes urbanos nocturnos. Al igual que en (Chacón et al., 2007), en (Cardaci et al., 2009) trabajan con un modelo matemático difuso de complejidad visual basado en la medida difusa de la entropía, para generar una medida objetiva de la complejidad de las imágenes. Para crear el modelo matemático de complejidad visual se utilizaron características locales y globales de las imágenes.

Se eligieron dos características locales, una es la información de los bordes y la otra son las simetrías locales que son obtenidas por la transformada discreta de simetría. De esta manera, los pixeles tienen tres valores: la intensidad de los bordes, la intensidad de borde umbralizada y binarizada de cero a uno, y la intensidad de simetría local. La medida de complejidad global es evaluada usando tres nuevas definiciones de entropía difusa las cuales son detalladas en (Di Gesù \& Roy, 2000). Los experimentos que realizaron son comparados con el criterio humano, para ver si existe correlación entre la subjetividad del humano para percibir la complejidad de las imágenes y su algoritmo. El método obtuvo una buena correlación entre las dimensiones espaciales y temporales de la complejidad asemejándose al criterio humano, lo que puede llevar a la posibilidad de incluir el procesamiento de información humana en un estándar para medir la complejidad visual. Por otro lado, en (Pham \& Yan, 2018) presentan una estadística de regularidad como una medida de complejidad de imágenes en términos de la entropía. El método que proponen consiste en aproximar la entropía de las imágenes en el marco de una cadena estacionaria de Markov, la cual es construida a partir de un gráfico ponderado que viene de la divergencia Kullback-Leibler de la imagen. Los resultados de este método demuestran que es un buen enfoque para cuantificar la complejidad de las 
imágenes basado en la aproximación de la entropía y que puede ser utilizado para la evaluación de la calidad de imágenes.

\subsection{Grado de compresión}

Existen varios métodos de complejidad de imágenes que utilizan el grado de compresión, sin embargo, como no es la única característica que utilizan, no todos se encuentran dentro de esta categoría. Solo se encuentra el trabajo de (A. Forsythe et al., 2011) ya que el grado de compresión es la característica principal de su método. Al igual que en (Guo et al., 2013) este trabajo se enfoca en medir la complejidad de pinturas artísticas pero para relacionarla con la estética y la belleza. Su método se basa en el grado de compresión GIF y el cálculo de la dimensión fractal. El grado de compresión GIF fue tomado en cuenta debido a que presentó una fuerte correlación con el criterio humano cuando se trata de pinturas artísticas. Los resultados demuestran que la combinación de la compresión GIF y la dimensión fractal dan una buena aproximación a la belleza de las pinturas en términos de la complejidad.

\subsection{Combinado}

Los métodos que se encuentran en esta categoría son aquellos que no se les pudo dar una clasificación específica ya que utilizan dos o más características principales. Los investigadores combinan las características ya que opinan que la complejidad de las imágenes depende de varios aspectos, pero se le da un peso diferente a cada una de ellas.

Por medio de una combinación lineal de características en (Ciocca et al., 2015; S. E. Corchs et al., 2016) crean un método para determinar la complejidad de imágenes basándose en características del dominio del espacio y la frecuencia, y las propiedades de color. Para la combinación lineal se utilizan varias características visuales simples y fueron seleccionadas de acuerdo con la literatura referente a complejidad de imágenes, estas características se listan a continuación:

- Contraste de cada pixel con sus vecinos a lo largo de la imagen.

- Cómo se correlaciona cada pixel con sus pixeles vecinos a lo largo de la imagen.

- La energía, la cual es la suma cuadrática de los elementos en GLCM (Matriz de Coocurrencia de Escala de Grises por sus siglas en inglés).

- La homogeneidad, la cual mide la cercanía de las distribuciones de los elementos en GLCM con respecto a la diagonal de GLCM.

- Factor de frecuencia, es la tasa entre la frecuencia correspondiente al $99 \%$ de la energía de la imagen y la frecuencia de Nyquist.

- La densidad de los bordes, la cual es obtenida aplicando el detector de bordes de Canny en las imágenes a escala de grises. 
- Tasa de compresión JPEG con un factor $Q=100$ en comparación a la imagen sin comprimir.

- Número de regiones calculadas usando el algoritmo de segmentación descrito en (Comaniciu \& Meer, 2002).

- Coloración de la imagen, la coloración de la imagen consiste en una combinación lineal de la media y la desviación estándar de la nube de pixeles en el plano de color (Hasler \& Suesstrunk, 2003).

- Número de colores distintos que existen en la imagen.

- La armonía de los colores (Solli \& Lenz, 2009).

- Congestión de características, se obtiene una sola métrica utilizando tres mapeos de desorden de las imágenes, representando la congestión de color, textura y orientación (Rosenholtz, Li, \& Nakano, 2007).

- Entropía de subbanda, esta métrica está relacionada al número de bits requeridos por subbanda para codificar la imagen (Rosenholtz et al., 2007).

Otro esquema que se ha trabajado es el uso de redes neuronales artificiales, en (Chen et al., 2015) Chen et al. las utilizan para generar un algoritmo que describa la complejidad de las imágenes cuantitativamente tomando en cuenta tres aspectos: la textura, información de los bordes y la región significativa. Las características de la textura son extraídas de la matriz de coocurrencia en escala de gris, las cuales corresponden a la energía, entropía, contraste, homogeneidad y correlación. De los bordes solo se utiliza como característica la tasa de bordes que existen en la imagen, debido a que relacionan que entre mayor cantidad de bordes tenga la imagen, más compleja será.

Para la región significativa se utilizan los coeficientes extraídos mediante la Transformada Discreta del Coseno. La clasificación de las características se realiza con una red neuronal artificial tipo feedforward la cual provee un valor que indica la tasa de complejidad de cada una de las imágenes, de esta manera cada imagen se clasifica dentro de tres categorías: No Compleja, Complicada y Muy Compleja. Una ventaja de este método es que puede calcular la complejidad de las imágenes de una manera automática e independiente del humano. En esta categoría también se encuentra el método propuesto en (Chikhman et al., 2012) donde desarrollaron un modelo para medir la complejidad de las imágenes donde utilizan características espaciales, características espacio-frecuenciales, una combinación de las propiedades espaciales y la Transformada de Fourier, y el tamaño de la imagen codificada en formato JPEG.

Se realiza un experimento psicofísico para comparar sus resultados donde algunas personas evalúan la complejidad de dos grupos de imágenes, un grupo son 15 jeroglíficos chinos con los que no están familiarizados y el otro grupo es de 24 imágenes con la silueta de objetos ya conocidos. La finalidad de escoger estos dos conjuntos de imágenes fue para analizar si se requiere medir de diferente manera la complejidad dependiendo del tipo de imagen utilizada. Los 
resultados indican que existe correlación entre los métodos que proponen para medir la complejidad y el criterio humano, sin embargo, concluyen que su modelo de medición puede ser usado para estimar la complejidad de las imágenes, pero para diferentes clases de imágenes se tienen que utilizar mediciones distintas. Por otro lado, en (Yaghmaee \& Jamzad, 2010) desarrollan un metodo basado en el concepto de Región de Interés (ROI por sus siglas en inglés). Las ROI son aquellas regiones de las imágenes que más atraen la atención humana. La idea principal de este método es encontrar las $\mathrm{ROI}$ en las imágenes dividiéndolas por bloques y posteriormente la complejidad de las imágenes se mide basándose en la intensidad, contraste, localización, bordes y textura.

El objetivo principal es aplicar la complejidad de la imagen para estimar la capacidad de marca de agua en imágenes a escala de grises, donde sus resultados demuestran que el método por $\mathrm{ROI}$ es mejor que los métodos de Complejidad Compositiva de Imagen (Rigau et al., 2005), Dimensión Fractal (Conci \& Aquino, 2005) y el método Quad Tree (Jamzad \& Yaghmaee, 2006) para calcular la capacidad de marca de agua. En (Da Silva et al., 2011) proponen un método para determinar la complejidad de las imágenes, no directamente en el análisis del contenido de las imágenes, sino a partir de la perspectiva de la complejidad a través de un filtro de atención. Utilizan mapas de atención, mapas sobresalientes y mapas de calor para el cálculo de la complejidad de las imágenes. También, muestran que los puntos de enfoque dinámicos generados por la atención no centralizada pueden generar una mejor estimación de la complejidad visual. Como trabajo futuro proponen enfocarse en el estudio de la complejidad en secuencias de video.

El algoritmo de agrupamiento K-means combinado con el algoritmo matemático SIFT (Transformación de Características Invariables a la Escala por sus siglas en inglés) es utilizado por (Huo, 2015, 2016b) para desarrollar un algoritmo que mide el desajuste de los objetos que se desean observar de los objetos más sobresalientes de las imágenes. Este desajuste es utilizado para medir que tan compleja es una imagen, tratando de representar el grado de dificultad que tienen los humanos para poner atención a los objetos de interés cuando existen objetos de no interés sobresalientes. Otro método objetivo de complejidad de imágenes que combina características es el propuesto por (Purchase et al., 2012), donde utilizan siete características: 1) la cantidad de colores distintos en la imagen, 2) la cantidad de colores después de un algoritmo que normaliza el color por regiones similares y adyacencia, 3) la cantidad de colores cuando un algoritmo de posterización es aplicado, 4) la cantidad de regiones después de segmentar la imagen, 5) el área de los bordes al utilizar el algoritmo de detección de Canny (Canny, 1986), 6) la desviación estándar de la intensidad de los pixeles con la imagen en escala de grises y 7) el grado de compresión JPEG, PNG y GIF. Los resultados de este método demostraron que es complicado asimilarse con el criterio humano mediante el uso de características simples, ya que la regresión no dio los resultados esperados. 
En el trabajo de (Guo, Asano, Asano, \& Kurita, 2011; Guo et al., 2012) no se propone un método para medir la complejidad de las imágenes, pero determinan cinco características que afectan la complejidad de la percepción visual de las texturas, estas características son: la regularidad, rugosidad, direccionalidad, densidad y comprensibilidad. Proponen un conjunto de métodos para medir cada una de estas características, la regularidad es estimada por una función de autocorrelación, la rugosidad es medida basándose en los cambios locales, la direccionalidad es indicada de acuerdo con las direcciones de los bordes, la densidad se calcula mediante la densidad de los bordes y la comprensibilidad es definida mediante el criterio humano. Por lo que, la definición de complejidad de las imágenes está en función de todas estas características basadas en un análisis de la textura. De esta manera, como trabajo futuro proponen crear un método para determinar la complejidad de las imágenes que involucre estas características. Además, se realizaron experimentos para verificar si cada una de las características propuestas se correlaciona con el criterio humano. En (Reinecke et al., 2013) predicen la primera impresión de la estética de las páginas web por medio de la cuantificación de la complejidad visual. Para medir la complejidad utilizan las siguientes características: el promedio del valor de los pixeles en el espacio de color HSV para matiz y saturación, la suma del valor promedio de saturación y su desviación estándar, la suma ponderada de la longitud trigonométrica de la desviación estándar, el número de hojas obtenidas por el método Quadtree, el número de áreas de imágenes, número de grupos de texto, relación de área con texto y sin texto, la simetría a lo largo del eje horizontal y vertical, y el equilibrio.

Los resultados demuestran que la complejidad visual tiene gran importancia para la impresión de los usuarios en páginas web, sin embargo, concluyen que las características utilizadas no son universales para evaluar complejidad visual, es decir, los usuarios de las páginas web perciben la complejidad de diferente manera de acuerdo con sus antecedentes demográficos. Otro método para determinar la complejidad que utiliza diversas características es el propuesto en (Sun et al., 2015), el cual es utilizado para analizar la relación de la complejidad con la estética y de esta manera poder predecir la belleza en las fotos. Las características utilizadas para medir la complejidad son extraídas de la composición, la estadística y la distribución de los pixeles. La composición es calculada utilizando el método momentos ortogonales variantes descrito en (Martín H., Santos, \& de Lope, 2010) y las características que se extraen son los segmentos, el color, la nitidez y la información de color relativo. Como información estadística se utilizan los bordes para contar el número de objetos, la curvatura, y textura calculan la entropía y áreas.

La distribución es representada como la combinación del histograma y sus diferencias con algunas plantillas de histograma predefinidas. De esta manera muestran que el nivel de complejidad que calculan por las características 
propuestas tiene una relación similar con la expectativa de belleza de los seres humanos en miles de fotos.

\section{Enfoques humanos}

Los métodos para determinar la complejidad de imágenes por enfoques humanos son aquellos que la medición de la complejidad se realiza mediante un estudio psicológico o físico de lo que sucede al presentar imágenes con diferentes grados de complejidad a los sujetos de pruebas. De esta manera, en esta sección se resumen los métodos encontrados que se basan en este tipo de técnica.

\subsection{Criterio humano}

Dentro de los artículos revisados acerca de la complejidad de imágenes, se encontraron algunos experimentos para poder evaluar el criterio humano y tener una medida subjetiva contra la cual comparar los métodos que proponen o para estudios psicológicos. La mayoría de los métodos consiste en presentar imágenes con diferentes grados de complejidad a personas, para que de esta manera se puedan realizar diferentes análisis y evaluaciones.

Un ground-truth para complejidad de imágenes es propuesto en (Da Silva et al., 2011), donde consideran que la complejidad está relacionada a la dificultad que se tiene para describirlas. Miden el tiempo de observación promedio de un conjunto de 148 imágenes de dos bases de datos que contienen información de movimiento ocular para imágenes con diferentes grados de complejidad (Bruce, Bruce, Tsotsos, \& Tsotsos, 2009; Le Meur, Le Callet, Barba, \& Thoreau, 2006). Se les pidió a 12 sujetos que observaran cada imagen de la base de datos el tiempo suficiente para poder describirlas con una cantidad media de detalles, posteriormente el tiempo fue normalizado, promediado y ordenado para poder obtener el ranking promedio de tiempo de observación. La complejidad de las imágenes la estiman por medio del área bajo la curva ROC, donde toman en cuenta la variación del tiempo de cada participante con la media. Un método diferente es propuesto en (Cardaci et al., 2009), donde participan dos grupos, uno de 50 sujetos y otro de 15 sujetos, para evaluar la complejidad de seis pinturas artísticas en tres categorías: baja, media y alta.

Los dos grupos pertenecen a diferentes universidades con diferentes carreras, esto se realizó con la finalidad de evitar algún sesgo cultural. Cada imagen se mostró durante $90 \mathrm{~s}$, después de este tiempo una persona les realizaba las siguientes preguntas a los participantes:

- ¿Definirías la imagen cómo agradable o molesta?

- ¿Definirías la imagen cómo silenciosa o llena de actividad? 
- ¿Cuántas personas había en la imagen?

- ¿Cuántas mujeres y hombres estaban en la imagen?

- ¿Definirías la imagen cómo violenta o alegre?

- ¿Hubo algún niño?

- ¿Qué estación del año era?

- ¿La escena es por la mañana o por la tarde?

- ¿Había animales en la escena?

- ¿Cuántos tonos de color distintos puedes recordar?

- ¿Ha percibido líneas curvas o rectas en la imagen?

- ¿Cuántas formas distintas había en la imagen?

Posteriormente, se evalúan las respuestas de cada uno de los sujetos para cada imagen, y con esto se mide el grado de complejidad basándose también en el tiempo que tardan para analizar cada una. Otro método se presenta en (S. E. Corchs et al., 2016), donde realizan 4 experimentos para evaluar la complejidad de las imágenes en una escala de 0 a 100, las imágenes son presentadas por un tiempo indefinido hasta que el sujeto envía su respuesta, la complejidad es determinada por la media del ranking que se le da a cada imagen. En el experimento 1 participan 26 sujetos, 15 mujeres y 11 hombres con edad promedio de 37 años, en un rango de 18 a 53 años, utilizan 49 imágenes de la base de datos RSIVL ("Imaging and Vision Laboratory, Department of Informatics, Systems and Communication, University of Milano-Bicocca", 2016).

Para el experimento 2 participan 16 mujeres y 20 hombres con edad promedio de 33 años, en un rango de 18 a 53, para este experimento se usan 49 imágenes diferentes a las del experimento 1, las cuales se encuentran en la base de datos LIVE (Sheik, Wang, Cormakc, \& Bovik, 2006; Sheikh, Sabir, \& Bovik, 2006; Wang, Bovik, Sheikh, \& Simoncelli, 2004) y IVL (S. Corchs, Gasparini, \& Schettini, 2014; "Imaging and Vision Laboratory, Department of Informatics, Systems and Communication, University of Milano-Bicocca", 2014). En el experimento 3 participan 17 sujetos 5 mujeres y 12 hombres con edad promedio de 35 años en un rango de 23 a 51, en este experimento se utilizan 54 imágenes de textura, el conjunto TXT1 de la base de datos VisTex ("MIT Media Lab, Vision Texture", s/f). Por último, para el experimento 4 participan 10 mujeres y 13 hombres con edad promedio de 28 años en un rango de 19 a 68, y para este experimento utilizan 68 imágenes de la base de datos RawFooT (Cusano, Napoletano, \& Schettini, 2016; "RawFoot DB - Imaging and Vision Laboratory Department of Systems, Informatics and Communication - University of MilanBicocca, Italy", 2016).

Por otro lado, en (Cavalcante et al., 2014) proponen un ranking subjetivo donde involucran a 40 sujetos de dos nacionalidades: 27 japonenses y 13 argelinos. En el experimento, los sujetos son colocados a una distancia aproximada de $80 \mathrm{~cm}$ del monitor donde se muestran las imágenes a evaluar. Los sujetos debían 
agrupar según su criterio las imágenes de los paisajes urbanos en tres grupos: simples, normales y complejos. Después, se les pidió que ordenaran las imágenes de menor a mayor complejidad para cada grupo. De esta manera, la complejidad de las imágenes fue estimada por la media del ranking que dieron cada uno de los sujetos participantes. En (Sun et al., 2015) también proponen un ranking subjetivo donde utilizan 80 fotografías (de animales, arquitectura, paisajes urbanos, flores, comida, retratos y naturaleza muerta) para que cinco sujetos, dos mujeres y tres hombres con edad entre 23 y 28 años evalúen su complejidad en una escala del uno al cinco, donde uno es una fotografía muy sencilla y cinco es una muy compleja. Para cada imagen se calcula la media y la desviación estándar de la complejidad prevista por los sujetos.

Otro método basado en el criterio humano es el propuesto por (Ramanarayanan et al., 2008), las pruebas piloto para entender como es la complejidad de las imágenes consistieron en que 21 sujetos ordenaran por grado de complejidad 40 imágenes obtenidas de la web. Cabe mencionar que no se les dio una explicación de lo que es complejidad, sino que cada sujeto realizó el experimento según su definición de complejidad. Después de este experimento se eligieron solamente 21 imágenes para las pruebas, donde los sujetos comparaban las imágenes por pares, diciendo cual es más compleja. Finalmente, los resultados obtenidos fueron comparados contra algunos métodos para determinar la complejidad de imágenes por enfoques computacionales, como el conteo de polígonos de escena y el grado de compresión de imágenes JPEG, donde se dieron cuenta de que no existía gran correlación. Por otro lado, en (Palumbo et al., 2014) miden la complejidad de imágenes mediante dos experimentos subjetivos $1 \mathrm{~A}$ y $2 \mathrm{~A}$. El experimento $1 \mathrm{~A}$ consistió en evaluar imágenes de patrones de bloques a blanco y negro. Participaron 10 sujetos con edad entre 19 y 45 años, cinco hombres y cinco mujeres. Los patrones de bloques fueron presentados a los sujetos aleatoriamente y tuvieron que evaluar su complejidad en una escala de 1 a 6 , donde 1 es muy simple y 6 muy compleja, en total se les presentaron 180 imágenes por lo que la evaluación duró aproximadamente 20 min. Los resultados de este experimento demostraron una correlación positiva con una medida de complejidad computacional basada en el grado de compresión GIF (Alex Forsythe, Mulhern, \& Sawey, 2008). El experimento 2A participaron 10 sujetos con edad entre 17 y 76 años, seis mujeres y seis hombres. Este experimento es similar al $1 \mathrm{~A}$ con la diferencia en que se utilizaron bloques de distintos tamaños. Para el experimento $2 \mathrm{~A}$ se obtuvo una alta correlación positiva con el grado de compresión GIF.

Además de proponer un método computacional, (Purchase et al., 2012) también proponen una medida subjetiva de la complejidad de imágenes donde recolectan la información por medio de un sitio web, esto con la finalidad de que lo puedan hacer desde el lugar donde se encuentren. La primera etapa del experimento consiste en pedirles a los sujetos que ordenen cuatro imágenes basándose en que tan complejas son para ellos, cada imagen es mostrada dos veces durante 
esta etapa, y cada sujeto realiza esta acción 30 veces, por lo tanto, se tiene un total de 60 imágenes distintas. En la segunda etapa se les muestran las 60 imágenes a los sujetos y se les pide que valoren la complejidad de cada una de acuerdo con la escala Likert de cinco puntos. Este experimento duró en promedio 13 minutos y lo realizaron 54 sujetos. Los resultados de este experimento demostraron que la evaluación subjetiva de complejidad de los humanos es consistente tanto individual como grupal.

\subsection{Reacción humana}

La complejidad de imágenes no solo ha sido estudiada para lograr definirla o cuantificarla, algunos trabajos de investigación se enfocan en estudiar cómo es la reacción de los seres humanos al observar imágenes con diferentes grados de complejidad. Las reacciones estudiadas pueden ser desde el movimiento ocular hasta las señales eléctricas que se generan en el cerebro.

El análisis del movimiento ocular al observar imágenes con diferentes grados de complejidad ha sido estudiado por (Bonev et al., 2013), y su hipótesis es que la complejidad de las imágenes está relacionada con la cantidad de tareas que se tienen que realizar para entenderlas. Para su experimento utilizan a ocho personas, y consiste en mostrarles imágenes mientras que se utiliza un dispositivo para registrar el movimiento ocular (SR Research Eyelink II) y otro para registrar el movimiento de la cabeza (VICON MX). Los autores comparan los resultados obtenidos contra un método que calcula la complejidad de las imágenes por medio de densidad de potencia espectral. Sus resultados difieren debido a que el movimiento de los ojos puede depender del tamaño de las imágenes, ya que, aunque se trate de la misma imagen pero con diferente tamaño, el movimiento de los ojos será menor o mayor. Por lo tanto, concluyen que el movimiento de los ojos para encontrar objetos en una imagen no está relacionada la complejidad de la imagen.

En (White et al., 2012) también analizan el movimiento ocular, pero con la finalidad de observar el comportamiento de los ojos al leer oraciones japonesas y los efectos en palabras largas o con complejidad visual alta. Para los experimentos participan diez estudiantes de la universidad de Teikyo en Japón, cuyo idioma natal es el japonés. El movimiento ocular fue monitoreado utilizando el dispositivo seguidor de ojos Dual Purkinje generación 5.5. Los participantes leen un total de 142 oraciones, de las cuales se les pide que las lean hasta que sean comprendidas totalmente. Los resultados demuestran que la complejidad de las oraciones influye significativamente en el tiempo de lectura.

Por otro lado, en (Roth et al., 2013) analizan el movimiento ocular para medir como es la experiencia de los usuarios en una página web ficticia con la finalidad de ver cómo afecta la localización de los objetos en tiendas en línea, páginas de noticias o de compañías. 40 sujetos participan en este experimento y el 
movimiento ocular es registrado mediante el dispositivo Tobii 1750 eye-tracker. Los resultados muestran que el colocar los objetos en posiciones esperadas de los usuarios y diseñar su apariencia de acuerdo con la orientación ayuda a mejorar la primera impresión de las páginas web y también la navegación en éstas.

En (Huo, 2016a) además de proponer un método para evaluar la complejidad de las imágenes, también realizó un experimento para medir si existe correlación entre su método y la actividad que tiene el cerebro humano mediante señales electroencefalográficas (EEG) cuando se observan imágenes con diferentes grados de complejidad. El experimento se realiza con cuatro hombres y cuatro mujeres con una edad promedio de 23.8 años donde se le pidió recordar cuantos objetos observan en una imagen que les es presentada en un monitor, las cuales van variando de simples a complejas. El número de objetos a recordar es de 3 a 50 en cada imagen. Los resultados obtenidos demuestran que existe correlación entre el método para medir la complejidad de imágenes que utilizan (Huo, 2015, 2016b) y el resultado del experimento con señales electroencefalográficas. En (Cho et al., 2016) también realizaron un estudio electroencefalográfico, además de uno magnetoencefalográfico (MEG) para medir la actividad cerebral de las personas cuando se les presentan imágenes 3D estereoscópicas, y de esta manera poder analizar su respuesta en imágenes con profundidad excesiva, diferentes tipos de complejidad en las texturas, objetos en movimiento, entre otras. La hipótesis de este trabajo es que la actividad cerebral puede aumentar a medida que aumenta la complejidad de forma de la imagen estereoscópica.

Para probar su hipótesis proponen un experimento que usa tres imágenes distintas, consiste en recolectar las señales EEG y MEG de 10 sujetos de pruebas sanos (seis hombres y cuatro mujeres con edad promedio de 24.4 años) y ver si existe correlación de la actividad cerebral con la complejidad de las imágenes. Después del análisis de los experimentos se presentaron varios resultados donde se comprueba que existe correlación entre la actividad cerebral del área occipital y el tipo de imágenes que se les fueron mostradas. Basándose también en un estudio magnetoencefalográfico, en (Hsu et al., 2011) estudian los efectos de la complejidad visual con un experimento que consiste en analizar las respuestas M100 y M170 en las zonas occipital y temporal de personas inglesas y chinas al observar caracteres chinos. Los resultados demostraron que para los ingleses y los chinos la M100 tiende a incrementar cuando se presentan caracteres con alto número de trazos, pero la M170 en el hemisferio izquierdo tiende a incrementar solo con los chinos cuando están leyendo los caracteres con alto número de trazos, y la M170 del hemisferio derecho incrementa cuando leen los caracteres menos complejos.

De esta manera, es posible darse cuenta de que la complejidad de imágenes sigue siendo subjetiva aún y cuando se analiza la actividad cerebral, lo cual es causado por una gran cantidad de aspectos psicológicos y demográficos. 


\section{Bases de datos utilizadas para medir la complejidad de imágenes}

En esta sección se muestran las bases de datos abiertas al público que se encontraron a través del análisis de la literatura, que han sido utilizadas para estudios de complejidad de imágenes. Algunas de ellas no son específicamente para la medición de complejidad de imágenes, pero debido a las características que presentan las imágenes en diferentes tipos de texturas, entornos reales con diversos números de objetos o imágenes con patrones artificiales, se consideró que pueden ser utilizadas para evaluar los métodos de medición de complejidad. En la Tabla 2 se muestra el nombre de las bases de datos encontradas, así como vínculo de la página web donde se encuentran.

La base de datos VisTex fue creada con la intención de proveer un conjunto de imágenes de texturas de alta calidad para aplicaciones de visión por computadora. RSIVL es una base de datos que contiene imágenes de escenarios reales la cual fue creada para analizar la influencia del color en la percepción de complejidad de imágenes y medir la complejidad de las imágenes. La base de datos IVL fue utilizada originalmente para la evaluación de la calidad de las imágenes, al igual que la base de datos LIVE y CSIQ Image Quality Database. Por otro lado, la base de datos RawFoot Texture fue diseñada para investigar la robustez de los métodos descriptores y de clasificación con respecto a las variaciones del color por los cambios de la iluminación. La base de datos Pictures for psycholinguistic studies, contiene un conjunto de imágenes que fueron diseñadas para analizar la familiaridad conceptual, la complejidad visual, la variabilidad de las imágenes, entre otras aplicaciones. Por último, la base de datos AVA contiene una inmensa cantidad de imágenes para el análisis visual de estética. 


\begin{tabular}{|c|c|}
\hline Base de datos & Ubicación (Vínculo) \\
\hline $\begin{array}{c}\text { Vision Texture (VisTex) ("MIT Media Lab, } \\
\text { Vision Texture", s/f) }\end{array}$ & http://vismod.media.mit.edu/vismod/imagery/VisionTexture/vistex.html \\
\hline $\begin{array}{c}\text { RSIVL ("Imaging and Vision Laboratory, } \\
\text { Department of Informatics, Systems and } \\
\text { Communication, University of Milano- } \\
\text { Bicocca", 2016) }\end{array}$ & http://www.ivl.disco.unimib.it/activities/complexity-perception-in-images/ \\
\hline $\begin{array}{c}\text { IVL (S. Corchs et al., 2014) ("Imaging and } \\
\text { Vision Laboratory, Department of } \\
\text { Informatics, Systems and Communication, } \\
\text { University of Milano-Bicocca", 2014) }\end{array}$ & http://www.ivl.disco.unimib.it/activities/imagequality/ \\
\hline LIVE (Sheik et al., 2006) & http://live.ece.utexas.edu/research/quality/ \\
\hline $\begin{array}{c}\text { Raw Food Texture (Cusano et al., 2016) } \\
\text { ("RawFoot DB - Imaging and Vision } \\
\text { Laboratory - Department of Systems, } \\
\text { Informatics and Communication - } \\
\text { University of Milan-Bicocca, Italy", 2016) }\end{array}$ & http://projects.ivl.disco.unimib.it/minisites/rawfoot/ \\
\hline $\begin{array}{c}\text { Pictures for psycholinguistic studies } \\
\text { (Bonin, Peereman, Malardier, Méot, \& } \\
\text { Chalard, s/f) }\end{array}$ & http://leadserv.u-bourgogne.fr/bases/pictures/ \\
\hline $\begin{array}{c}\text { CSIQ/Image Quality Database (Chandler, } \\
\text { 2010) (Larson \& Chandler, 2010) }\end{array}$ & http://vision.eng.shizuoka.ac.jp/mod/page/view.php?id=23 \\
\hline $\begin{array}{c}\text { AVA (Murray, Marchesotti, \& Perronnin, } \\
\text { 2012) (Murray, Marchesotti, \& Perronnin, } \\
\text { s/f) }\end{array}$ & https://github.com/mtobeiyf/ava_downloader \\
\hline
\end{tabular}

Tabla 2. Bases de datos utilizadas para medir la complejidad de imágenes.

\section{Análisis}

Los 34 métodos para determinar la complejidad de imágenes que se encontraron en la literatura fueron obtenidos mediante el análisis de 28 artículos. Estos métodos fueron analizados y resumidos en la Sección 3 y 4. En algunos artículos se proponen hasta dos diferentes métodos, normalmente uno por enfoques computacionales y otro basado en enfoques humanos. Los 34 métodos encontrados se clasificaron en seis categorías con base en el tipo de características que utilizan para determinar la complejidad, estas categorías son: información de bordes, información del color y/o intensidad, grado de compresión, combinado, criterio humano y reacción humana. En la Figura 1 se muestra un gráfico donde se indica la cantidad de métodos por cada categoría propuesta. Cabe mencionar que debido a que no se tiene una definición concreta de lo que es complejidad de imágenes, muchos investigadores del área de procesamiento digital de imágenes o visión por computadora la utilizan de una forma indirecta, es decir, utilizan características para realizar ajustes en los parámetros de sus algoritmos que también son utilizadas para el cálculo de la complejidad, por ejemplo, la entropía es utilizada para ajustar parámetros en algunos algoritmos, y existen investigadores que relacionan directamente la entropía con la complejidad de las imágenes.

Para la categoría información de bordes se encontraron dos métodos, para información de color y/o intensidad siete, para grado de compresión solo se 
encontró uno y en el caso de combinado se encontraron diez. Se encontraron también ocho métodos basados en el criterio humano y seis en la reacción humana. Las categorías información de bordes y grado de compresión son las que contienen una menor cantidad de métodos. Sin embargo, por lo general estas características son utilizadas en combinación con otras. Por lo que, algunas de las medidas en la categoría combinado incluyen también características de bordes y grado de compresión. La categoría combinado es la que contiene la mayor cantidad de métodos para determinar la complejidad de imágenes, esto es debido a que la mayoría de los investigadores optan por usar más de una característica para realizar la medición, ya que tratan de aproximarse más al criterio humano y definen que la complejidad está en función de diversas características. La categoría criterio humano es la segunda con mayor cantidad, dentro de esta categoría entran los métodos que tienen como finalidad el análisis de aspectos psicológicos o también tener una comparación para los métodos computacionales propuestos.

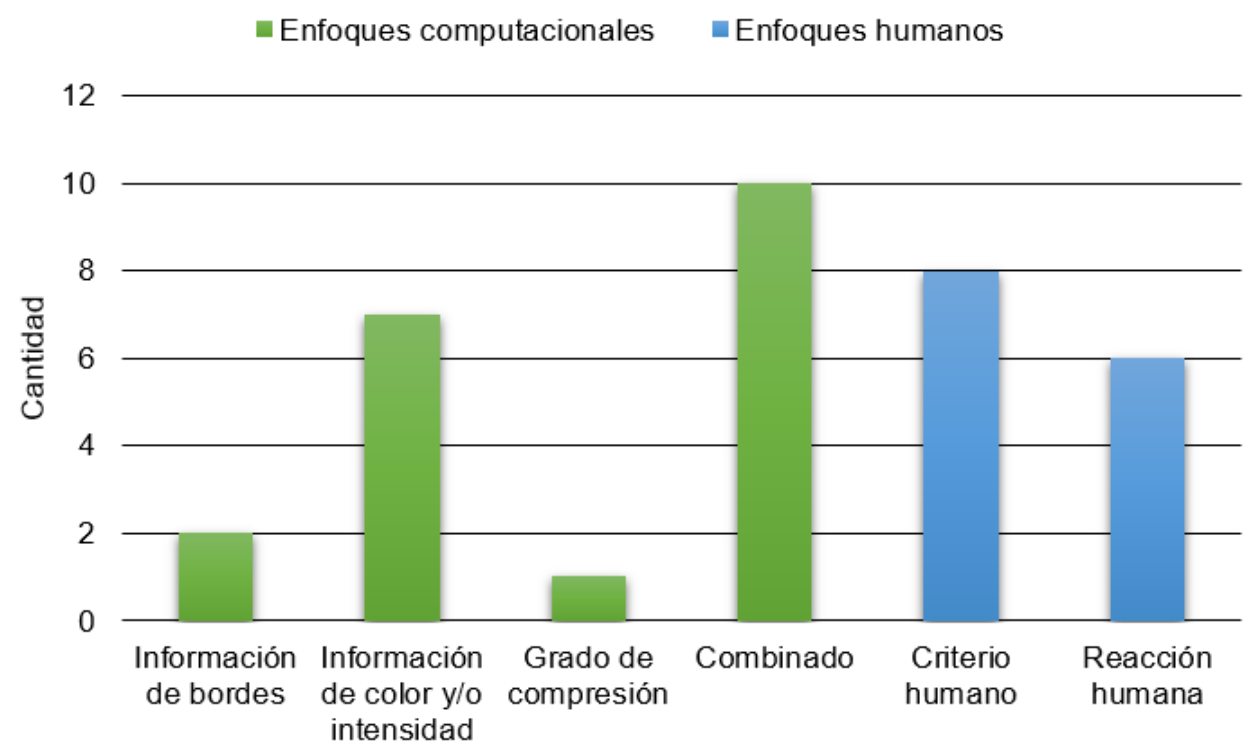

Figura 1. Cantidad de métodos por categoría.

La búsqueda de artículos se realizó considerando artículos del 2005 a la actualidad, y como se puede observar en la gráfica de la Figura 2 la mayor cantidad de métodos publicados fue del 2009 al 2016. Los años donde se encontraron la mayor cantidad de publicaciones fue en el 2012 y 2016 con cinco métodos. Sin embargo, a partir del 2017 los métodos de complejidad de imágenes publicados decayeron considerablemente, donde solo se encontró uno. Pero, las características utilizadas para la medición de la complejidad de imágenes siguen siendo utilizadas para desarrollar algoritmos de áreas como procesamiento digital de imágenes y visión por computadora, por lo que se concluye que la complejidad de imágenes no siempre es estudiada de una forma directa, y se sigue realizando investigación en esta área aún y cuando no se le dé este nombre en específico. 


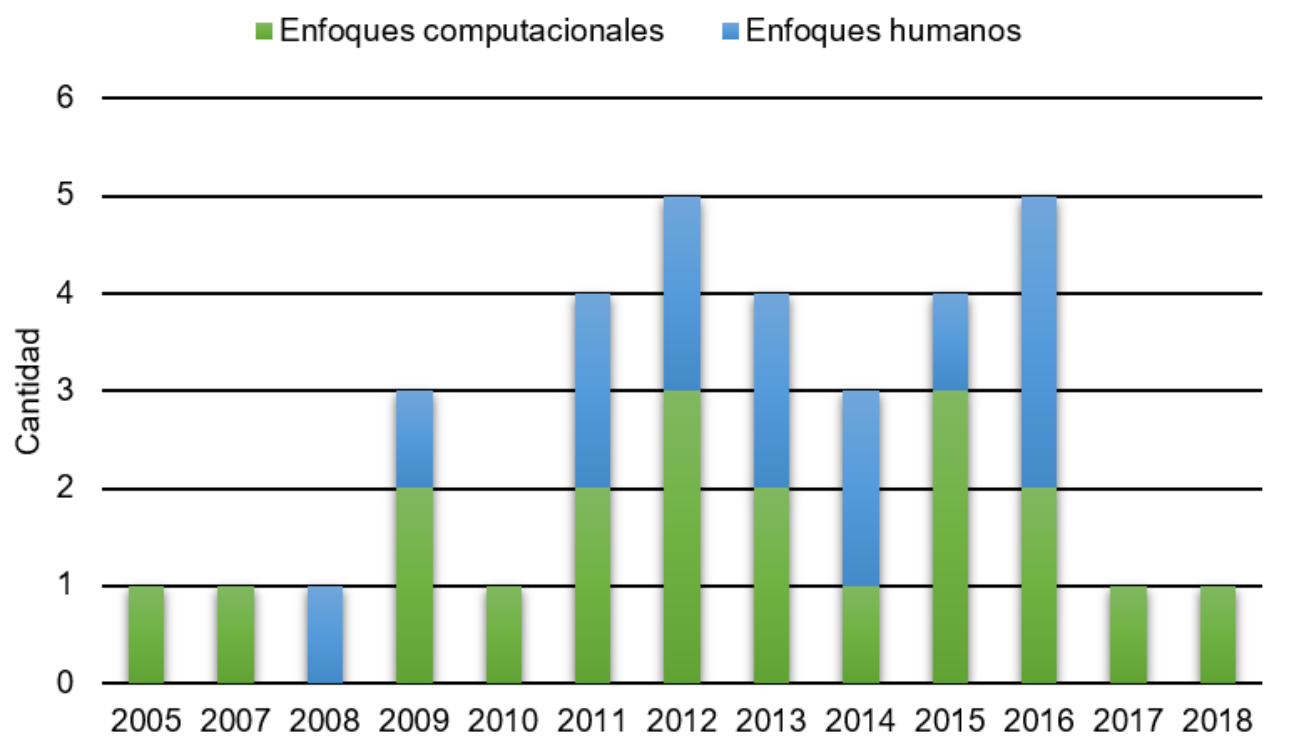

Figura 2. Cantidad de métodos encontrados por año de publicación.

En la gráfica mostrada en la Figura 3 se observan las características relevantes que utilizan los métodos de complejidad de imágenes por enfoques computacionales estudiados en este artículo. Las características más utilizadas son la información de color, la cual es utilizada diez veces y la información de bordes que se utiliza ocho veces. Seguidamente, se encuentra la entropía como característica para este tipo de medición, la cual es utilizada por cinco diferentes métodos, y el grado de compresión y las regiones de la segmentación se utilizan cuatro veces. Las características restantes son aquellas que se utilizan para casos particulares de cada una de las mediciones de complejidad propuestas. Con esto, es posible darse cuenta de que la mayoría de los investigadores relaciona a la complejidad de imágenes con la información que provee el color ya que de aquí se pueden extraer datos importantes para asemejarse a el criterio humano, y la información de los bordes que provee información de la cantidad de detalles contenidos, así como la cantidad de objetos. 


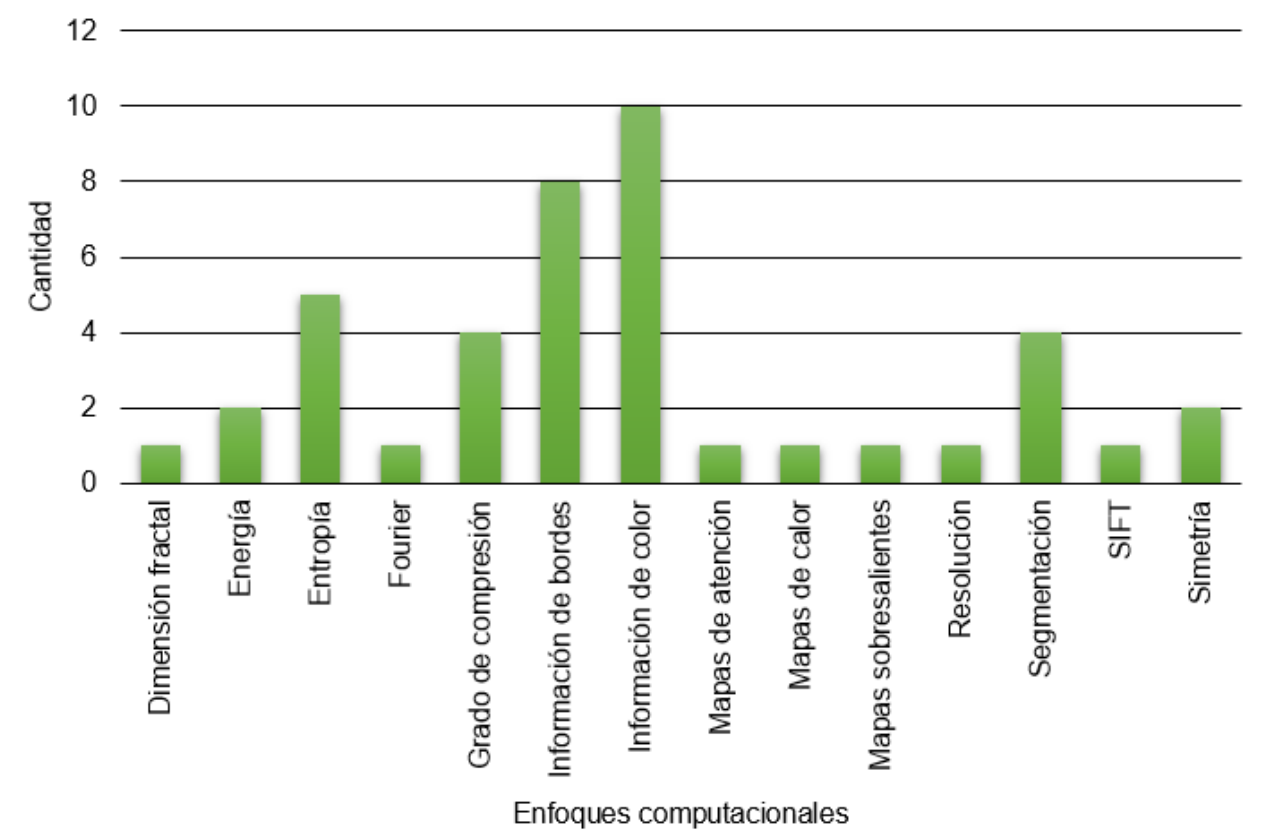

Figura 3. Cantidad de características utilizadas por los enfoques computacionales.

Con lo referente a los enfoques humanos, se encontraron siete tipos de características o métodos para la medición de la complejidad de imágenes, los cuales son mostrados en la Figura 4. La más utilizada es la media del criterio humano, la cual trata de que los sujetos participantes en los experimentos evalúen dentro de una escala la complejidad de cada imagen que se les presenta. Tres medidas donde se trabaja con el movimiento ocular fueron encontradas, para este tipo de método la complejidad de imágenes depende proporcionalmente del movimiento ocular necesario para analizar las imágenes. También, las señales EEG y MEG fueron estudiadas para cuantificar la complejidad, las cuales fueron utilizadas dos veces cada una. Además, se utilizó el tiempo de observación de las imágenes y el realizar un cuestionario para evaluar el criterio.

Como se aprecia en la información anterior, se encontraron diversas aplicaciones para los métodos de medición de complejidad de imágenes, algunos métodos son aplicados para el desarrollo de algoritmos computacionales y otros para analizar la impresión de las personas a los diferentes grados de complejidad. De los 34 métodos analizados, 19 de ellos tienen una aplicación práctica, distribuidos en la creación de algoritmos computaciones o análisis de cómo perciben la complejidad las personas. Los otros 15 métodos que no tienen una aplicación práctica son propuestos principalmente con la finalidad de demostrar que las medidas computacionales de complejidad de imágenes se correlacionan con el criterio humano y viceversa. 


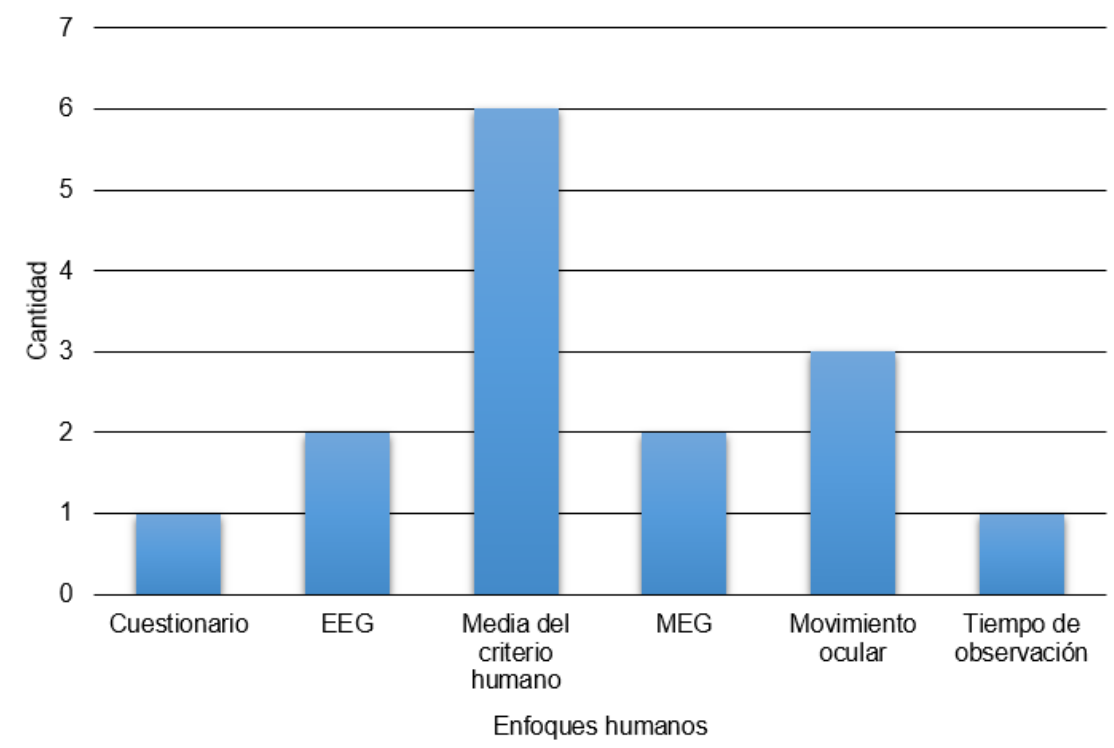

Figura 4. Cantidad de características utilizadas por los enfoques humanos.

\section{Resultados y conclusiones}

Como se pudo observar a lo largo de este artículo, la cantidad de publicaciones donde se proponen métodos para determinar la complejidad de imágenes es escaza, esto puede ser debido a que no siempre es utilizada directamente. Sin embargo, la medición de la complejidad de imágenes ha contribuido a que muchos algoritmos computacionales del área de procesamiento digital de imágenes, visión por computadora, entre otras, cada vez sean menos dependientes del humano, es decir contribuye a la autoadaptibilidad, la cual es una cualidad importante ya que la tendencia de los algoritmos hoy en día es depender menos de la interacción humana. También, puede contribuir en lo referente a la impresión humana, como el diseño de páginas web con un acomodo de objetos más eficientes y estético, saber cómo será la experiencia de los usuarios al navegar en la web y la predicción de la belleza en pinturas artísticas. Además, puede contribuir en diversos estudios psicológicos.

\section{Referencias}

Bonev, B., Chuang, L. L., \& Escolano, F. (2013). How do image complexity, task demands and looking biases influence human gaze behavior? Pattern Recognition Letters, 34(7), 723-730. http://doi.org/10.1016/j.patrec.2012.05.007

Bonin, P., Peereman, R., Malardier, N., Méot, A., \& Chalard, M. (s/f). Pictures and norms for psycholinguistic studies. Recuperado el 2 de mayo de 2018, a partir de http://leadserv.u-bourgogne.fr/bases/pictures/ 
Bruce, N. D. B., Bruce, N. D. B., Tsotsos, J. K., \& Tsotsos, J. K. (2009). Saliency, attention, and visual search: An information theoretic approach. Journal of Vision, 9(2009), 1-24. http://doi.org/10.1167/9.3.5.Introduction

Canny, J. (1986). A computational approach to edge detection. IEEE transactions on pattern analysis and machine intelligence, 8(6), 679-698. http://doi.org/10.1109/TPAMI.1986.4767851

Cardaci, M., Di Gesù, V., Petrou, M., \& Tabacchi, M. E. (2009). A fuzzy approach to the evaluation of image complexity. Fuzzy Sets and Systems, 160(10), 14741484. http://doi.org/10.1016/j.fss.2008.11.017

Cavalcante, A., Mansouri, A., Kacha, L., Barros, A. K., Takeuchi, Y., Matsumoto, N., \& Ohnishi, N. (2014). Measuring streetscape complexity based on the statistics of local contrast and spatial frequency. PLOS ONE, 9(2), 1-13. http://doi.org/10.1371/journal.pone.0087097

Chacón, M. I., Aguilar D., L. E., \& Delgado S., A. (2002). Fuzzy adaptive edge definition based on the complexity of the image. En IEEE International Conference on Fuzzy Systems (Vol. 2, pp. 675-678). http://doi.org/10.1109/FUZZ.2001.1009045

Chacón, M. I., Corral S., A. D., \& Sandoval R., R. (2007). A Fuzzy Approach on Image Complexity Measure. Computación y Sistemas, 10(3), 268-284. Recuperado a partir de http://www.scielo.org.mx/pdf/cys/v10n3/v10n3a6.pdf

Chandler, D. M. (2010). Most apparent distortion: full-reference image quality assessment and the role of strategy. Journal of Electronic Imaging, 19(1), 1-21. http://doi.org/10.1117/1.3267105

Chen, Y.-Q., Duan, J., Zhu, Y., Qian, X.-F., \& Xiao, B. (2015). Research on the image complexity based on neural network. En Proceedings of the 2015 International Conference on Machine Learning and Cybernetics (pp. 295-300).

Chikhman, V., Bondarko, V., Danilova, M., Goluzina, A., \& Shelepin, Y. (2012). Complexity of images: experimental and computational estimates compared. Perception, 41 (6), 631-647. http://doi.org/10.1068/p6987

Cho, H., Kang, M. K., Ahn, S., Kwon, M., Yoon, K. J., Kim, K., \& Jun, S. C. (2016). Cortical responses and shape complexity of stereoscopic image - A simultaneous EEG/MEG study. NeuroSignals, 24(1), 102-112. http://doi.org/10.1159/000442617 
Ciocca, G., Corchs, S., \& Gasparini, F. (2015). Complexity Perception of Texture Images. En Springer International Publishing Switzerland 2015 (Vol. 9281, pp. $119-$ 126). http://doi.org/10.1007/978-3-319-23222-5

Comaniciu, D., \& Meer, P. (2002). Mean Shift: A Robust Approach Toward Feature Space Analysis. IEEE Transactions on Pattern Analysis and Machine Intelligence, 24(5), 1-18. http://doi.org/10.1109/34.1000236

Conci, A., \& Aquino, F. (2005). Fractal coding based on image local fractal dimension. Computational \& Applied Mathematics, 24(1), 83-98. http://doi.org/10.1590/S0101-82052005000100005

Corchs, S. E., Ciocca, G., Bricolo, E., \& Gasparini, F. (2016). Predicting complexity perception of real world images. PLoS ONE, 11(6), 1-22. http://doi.org/10.1371/journal.pone.0157986

Corchs, S., Gasparini, F., \& Schettini, R. (2014). No reference image quality classification for JPEG-distorted images. Digital Signal Processing: A Review Journal, 30, 86-100. http://doi.org/10.1016/j.dsp.2014.04.003

Corral S., A. D. (2003). Modeling edge perception using fuzzy logic. Master Thesis.

Cusano, C., Napoletano, P., \& Schettini, R. (2016). Evaluating color texture descriptors under large variations of controlled lighting conditions. Journal of the Optical Society of America, 33(1), 17-30. http://doi.org/10.1364/JOSAA.33.000017

Da Silva, M. P., Courboulay, V., \& Estraillier, P. (2011). Image Complexity Measure Based on Visual Attention. En IEEE International Conference On Image Processing (pp. 3281-3284).

Di Gesù, V., \& Roy, S. (2000). Fuzzy measures for image distance. En Advances in Fuzzy Systems and Itelligent Technologies. NL: Shaker Publishing.

Forsythe, A. (2009). Visual Complexity: Is That All There Is ? Complexity, 5639, 158166. http://doi.org/10.1007/978-3-642-02728-4_17

Forsythe, A., Mulhern, G., \& Sawey, M. (2008). Confounds in pictorial sets: The role of complexity and familiarity in basic-level picture processing. Behavior Research Methods, 40(1), 116-129. http://doi.org/10.3758/BRM.40.1.116

Forsythe, A., Nadal, M., Sheehy, N., Cela-Conde, C. J., \& Sawey, M. (2011). Predicting beauty: Fractal dimension and visual complexity in art. British Journal of Psychology, 102(1), 49-70. http://doi.org/10.1348/000712610X498958 
Guo, X., Asano, C. M., Asano, A., \& Kurita, T. (2011). Visual complexity perception and texture image characteristics. En 2011 International Conference on Biometrics and Kansei Engineering (pp. 260-265). http://doi.org/10.1109/ICBAKE.2011.13

Guo, X., Asano, C. M., Asano, A., Kurita, T., \& Li, L. (2012). Analysis of texture characteristics associated with visual complexity perception. Optical Review, 19(5), 306-314. http://doi.org/10.1007/s10043-012-0047-1

Guo, X., Kurita, T., Muraki Asano, C., \& Asano, A. (2013). Visual complexity assessment of painting images. En Image Processing (ICIP), 2013 20th IEEE International Conference on (pp. 388-392).

Hasler, D., \& Suesstrunk, S. E. (2003). Measuring colourfulness in natural images. En Electronic Imaging 2003 (pp. 87-95). http://doi.org/10.1117/12.477378

Heaps, C., \& Handel, S. (1999). Similarity and features of natural textures. Journal of Experimental Psychology: Human Perception and Performance, 25(2), 299320. http://doi.org/10.1037/0096-1523.25.2.299

Hsu, C. H., Lee, C. Y., \& Marantz, A. (2011). Effects of visual complexity and sublexical information in the occipitotemporal cortex in the reading of Chinese phonograms: A single-trial analysis with MEG. Brain and Language, 117(1), 1-11. http://doi.org/10.1016/j.bandl.2010.10.002

Huo, J. (2015). A measurement method for the mismatch between the image target and salient points as a metric for image complexity. En Science and Information Conference, SAl 2015 (pp. 645-649). http://doi.org/10.1109/SAl.2015.7237210

Huo, J. (2016a). An image complexity measurement algorithm with visual memory capacity and an EEG study. En SAI Computing Conference (pp. 264268). http://doi.org/10.1109/SAI.2016.7555993

Huo, J. (2016b). Image Complexity and Visual Working Memory Capacity. Emerging Trends and Advanced Technologies for Computational Intelligence, 647, 301-314. http://doi.org/10.1007/978-3-319-33353-3

Imaging and Vision Laboratory, Department of Informatics, Systems and Communication, University of Milano-Bicocca. (2014). Recuperado el 2 de mayo de 2018, a partir de http://www.ivl.disco.unimib.it/activities/image-quality

Imaging and Vision Laboratory, Department of Informatics, Systems and Communication, University of Milano-Bicocca. (2016). Recuperado el 2 de mayo de 2018, a partir de http://www.ivl.disco.unimib.it/activities/complexityperception-in-images 
Ivanovici, M. (2017). A Naive Complexity Measure for Color Texture Images. En 2017 International Symposium on Signals, Circuits and Systems (ISSCS) (pp. 1-4).

Jamzad, M., \& Yaghmaee, F. (2006). Achieving higher stability in watermarking according to image complexity. Scientia Iranica Journal, 13(4), 404-412. Recuperado a partir de http://www.plan.sid.ir/en/VEWSSID/J_pdf/95520060405.pdf

Kolmogorov, A. N. (1968). Three approaches to the quantitative definition of information. International Journal of Computer Mathematics, 2(1-4), 157-168. http://doi.org/10.1080/00207166808803030

Larson, E. C., \& Chandler, D. M. (2010). Databases: CSIQ Image Quality Database. Recuperado el 2 de mayo de 2018, a partir de http://vision.eng.shizuoka.ac.jp/mod/page/view.php?id=23

Le Meur, O., Le Callet, P., Barba, D., \& Thoreau, D. (2006). A coherent computational approach to model bottom-up visual attention. IEEE Transactions on Pattern Analysis and Machine Intelligence, 28(5), 802-817. http://doi.org/10.1109/TPAMI.2006.86

Machado, P., Romero, J., Nadal, M., Santos, A., Correia, J., \& Carballal, A. (2015). Computerized measures of visual complexity. Acta Psychologica, 160, 43-57. http://doi.org/10.1016/j.actpsy.2015.06.005

Martín H., J. A., Santos, M., \& de Lope, J. (2010). Orthogonal variant moments features in image analysis. Information Sciences, 180(6), 846-860. http://doi.org/10.1016/j.ins.2009.08.032

MIT Media Lab, Vision Texture. (s/f). Recuperado el 2 de mayo de 2018, a partir de http://vismod.media.mit.edu/vismod/imagery/VisionTexture/

Murray, N., Marchesotti, L., \& Perronnin, F. (s/f). AVA Dataset. Recuperado el 5 de mayo de 2018, a partir de https://github.com/mtobeiyf/ava_downloader

Murray, N., Marchesotti, L., \& Perronnin, F. (2012). AVA: A large-scale database for aesthetic visual analysis. Proceedings of the IEEE Computer Society Conference on Computer Vision and Pattern Recognition, 2408-2415. http://doi.org/10.1109/CVPR.2012.6247954

Ning, J., Zhang, L., Zhang, D., \& Wu, C. (2010). Interactive image segmentation by maximal similarity based region merging. Pattern Recognition, 43(2), 445-456. http://doi.org/10.1016/j.patcog.2009.03.004 
Palumbo, L., Makin, A. D. J., \& Bertamini, M. (2014). Examining visual complexity and its influence on perceived duration. Journal of Vision, 14(14), 1-18. http://doi.org/10.1167/14.14.3.doi

Perki, J., \& Hyvarinen, A. (2009). Modelling image complexity by independent component analysis, with application to content-based image retrieval. En Artificial Neural Networks-ICANN 2009 (pp. 704-714). http://doi.org/10.1007/9783-642-04277-5_71

Pham, T. D., \& Yan, H. (2018). A regularity statistic for images. Chaos, Solitons and Fractals, 106, 227-232. http://doi.org/10.1016/j.chaos.2017.11.033

Purchase, H. C., Freeman, E., \& Hamer, J. (2012). An Exploration of Visual Complexity. En International Conference on Theory and Application of Diagrams (Vol. 7352, pp. 200-213). http://doi.org/10.1007/978-3-642-31223-6_22

Ramanarayanan, G., Bala, K., Ferwerda, J. a., \& Walter, B. (2008). Dimensionality of Visual Complexity in Computer Graphics Scenes. En Proceedings of SPIE 6806, Human Vision and Electronic Imaging XIII (pp. 1-12). http://doi.org/10.1117/12.767029

RawFoot DB - Imaging and Vision Laboratory - Department of Systems, Informatics and Communication - University of Milan-Bicocca, Italy. (2016). Recuperado el 2 de mayo de 2018, a partir de http://projects.ivl.disco.unimib.it/rawfoot

Reinecke, K., Yeh, T., Miratrix, L., Mardiko, R., Zhao, Y., Liu, J., \& Gajos, K. Z. (2013). Predicting users' first impressions of website aesthetics with a quantification of perceived visual complexity and colorfulness. En Proceedings of the SIGCHI Conference on Human Factors in Computing Systems (pp. 2049-2058). http://doi.org/10.1145/2470654.2481281

Rigau, J., Feixas, M., \& Sbert, M. (2005). An Information-Theoretic Framework for Image Complexity. En Computational Aesthetics in Graphics, Visualization and Imaging (pp. 177-184). http://doi.org/10.2312/COMPAESTH/COMPAESTH05/177184

Rosenholtz, R., Li, Y., \& Nakano, L. (2007). Measuring visual clutter. Journal of vision, $7(2)$, 1-22. http://doi.org/10.1167/7.2.17

Roth, S. P., Tuch, A. N., Mekler, E. D., Bargas-Avila, J. A., \& Opwis, K. (2013). Location matters, especially for non-salient features-An eye-tracking study on the effects of web object placement on different types of websites. International Journal of Human Computer Studies, 71(3), 228-235. http://doi.org/10.1016/j.ijhcs.2012.09.001 
Sheik, H., Wang, Z., Cormakc, L., \& Bovik, A. (2006). LIVE Image Quality Assessment Database Release 2. Recuperado el 2 de mayo de 2018, a partir de http://live.ece.utexas.edu/research/quality/

Sheikh, H. R., Sabir, M. F., \& Bovik, A. C. (2006). Image Quality Assessment Algorithms. Image Processing, IEEE Transactions on, 15(11), 3441-3452. http://doi.org/10.1109/TPCG.2004.1314471

Snodgrass, J. G., \& Vanderwart, M. (1980). A standardised set of 260 pictures: normal for name agreement, familiarity and visual complexity. Journal of Experimental Psychology: Human Learning and Memory, 6(2), 174-215.

Solli, M., \& Lenz, R. (2009). Color harmony for image indexing. En 2009 IEEE 12th International Conference on Computer Vision Workshops, ICCV Workshops 2009 (pp. 1885-1892). http://doi.org/10.1109/ICCVW.2009.5457512

Sun, L., Yamasaki, T., \& Aizawa, K. (2015). Relationship Between Visual Complexity and Aesthetics: Application to Beauty Prediction of Photos. En Computer Vision - ECCV 2014 Workshops (Vol. 8925, pp. 20-34). http://doi.org/10.1007/978-3-319$16199-0$

Technology, M. I. of. (2002). Vision Texture. Recuperado el 14 de abril de 2018, a partir

http://vismod.media.mit.edu/vismod/imagery/VisionTexture/vistex.html

Wang, Z., Bovik, A. C., Sheikh, H. R., \& Simoncelli, E. P. (2004). Image quality assessment: From error visibility to structural similarity. IEEE Transactions on Image Processing, 13(4), 600-612. http://doi.org/10.1109/TIP.2003.819861

White, S. J., Hirotani, M., \& Liversedge, S. P. (2012). Eye movement behaviour during reading of Japanese sentences: Effects of word length and visual complexity. Reading and Writing, 25(5), 981-1006. http://doi.org/10.1007/s1 1145010-9289-0

Yaghmaee, F., \& Jamzad, M. (2010). Estimating watermarking capacity in gray scale images based on image complexity. Eurasip Journal on Advances in Signal Processing, 2010, 1-9. http://doi.org/10.1155/2010/851920

Yoon, K. J., \& Kweon, I. S. (2001). Color image segmentation considering the human sensitivity for color pattern variations. En Photonics Boston, SPIE, Page (s) (Vol. 4572, pp. 269-278). http://doi.org/10.1117/12.444191 


\section{Notas biográficas}

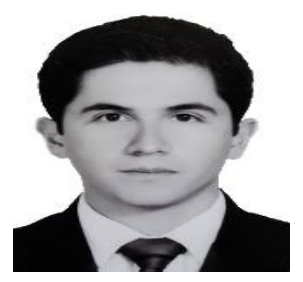

Luis Madrid Herrera. Obtuvo el grado de Ingeniero en Mecatrónica del Instituto Tecnológico Superior de Nuevo Casas Grandes en 2015 y el grado de Maestro en Ciencias en Ingeniería Electrónica del Instituto Tecnológico de Chihuahua en 2018. Actualmente, es estudiante de Doctorado en Ciencias en Ingeniería Electrónica del Instituto Tecnológico de Chihuahua. Su investigación es en el área de procesamiento digital de señales e imágenes, enfocado a complejidad de imágenes e interfaces cerebro computadora.

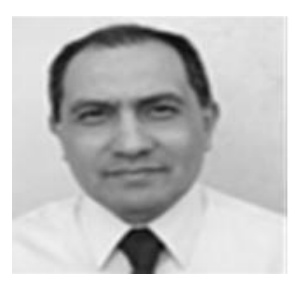

Mario Ignacio Chacón Murguía. (M'86-SM'04) obtuvo el grado de Ingeniero Industrial en Electrónica, 1982, y el grado de Maestro en Ciencias en Ingeniería Electrónica, en 1985 del Instituto Tecnológico de Chihuahua, México, y el grado de Doctor en Ciencias, 1998, de la Universidad Estatal de Nuevo México, EEUU. Ha desarrollado varios proyectos para varias compañías. Actualmente trabaja como Profesor Investigador en el Instituto Tecnológico de Chihuahua. Ha publicado más de 175 trabajos y publicado 3 libros. Su investigación actual incluye Visión por Computadora y procesamiento de imágenes y señales usando Inteligencia Computacional. El Dr. Chacón es miembro Senior de la IEEE, y miembro de las sociedades IEEE; Inteligencia computacional, Procesamiento Digital de Señales y Miembro del SNI en México.

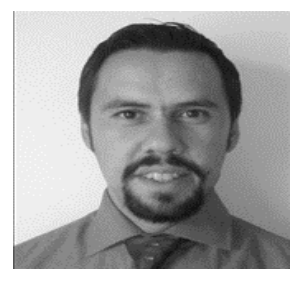

Juan Alberto Ramírez Quintana. Recibió los grados de ingeniería (2004), maestría (2007) y doctorado (2014) en ingeniería electrónica del Instituto Tecnológico de Chihuahua, México. Actualmente trabaja como profesor-investigador en el Instituto Tecnológico de Chihuahua. Sus áreas de interés son visión por computadora, procesamiento de señales, percepción visual, inteligencia computacional. El Dr. Ramírez es miembro del Sistema Nacional de Investigadores de México.

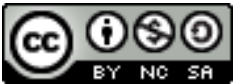

Esta obra está bajo una licencia de Creative Commons Reconocimiento-NoComercial-Compartirlgual 2.5 México. 